\title{
"QUÁRA" DO JABUTI: REFLEXÕES SOBRE O CICLO DO JABUTI
}

\author{
JABUTI'S “QUÁRA”: \\ REFLEXIONS ON THE JABUTI'S CYCLE
}

\author{
Rafael Bonavina ${ }^{1}$ \\ Universidade de São Paulo
}

Resumo: Este trabalho levantou uma hipótese para explicar a supressão da tradução da palavra "quára" no conto VIII do ciclo do Jabuti encontrado em O Selvagem, de Couto Magalhães. Para isso, começamos nossa análise pelo gênero textual das narrativas, levando em conta diversas versões do ciclo do Jabuti. Em seguida fazemos algumas considerações a respeito da caracterização do personagem em si mesmo. A partir dessas reflexões, depreendeu-se que a supressão ocorreu por exigência do mercado editorial brasileiro do século XIX.

Palavras-Chave: Literatura Indígena; Mito; Ciclo do Jabuti.

1 Endereço eletrônico: rafaelbonavina@gmail.com. 
Abstract: This study tries to explain the missing translation of the word "quara", found in the VIII of the Jabuti cycle of O Selvagem, by Couto Magalhães. For this, we consider the genre of the narratives, analyzing various versions of the Jabuti cycle. Then we discuss the characterization of the Jabuti himself in these narratives. From these reflections, we deduced that the word wqs suppressed because of the 19th century Brazilian publishing market.

Keywords: Indigenous Literature; Myth; Jabuti's Cycle.

\section{CONSIDERAÇÕES INICIAIS}

Ao compararmos o ciclo do Jabuti com as narrativas cosmogônicas, notase uma evidente contradição entre a potência dos demiurgos e do Jabuti. Nas versões consultadas, o Jabuti não detém poderes mágicos, pelo contrário, é limitado pelas suas condições físicas, o que serve de mote para algumas das históricas, e falaremos disso em momento oportuno. Tampouco se poderia considerar que o Jabuti seria um herói cultural, de quem depende a fixação da ordem social (MELETÍNSKI, 2019, p. 31), pois nem sempre lhe são atribuídas explicações etiológicas dos elementos culturais². Dessa forma podemos descartar a classificação como mitos antigos, em que figuram principalmente os personagens responsáveis pelo estabelecimento da ordem cósmica, portanto é seguro afirmar que o ciclo do Jabuti é de origem mais recente.

A partir dessa constatação, devemos levar em conta o grau de desmitologização do Jabuti para classificar melhor suas narrativas. A princípio, por causa de sua astúcia, ele poderia ser considerado um trickster, mas sua comparação com um trickster de mitos mais antigos, como o Makunaima dos taurepangues, impediria essa classificação. O Jabuti não possui poderes mágicos, por exemplo, ele não é capaz de transformar as coisas em pedra ou de realizar as

2 É preciso ressaltar que a versão do ciclo do jabuti contada por Mayuluaípu da tribo taurepangue, registrada por Koch-Grünberg, termina com a transformação do jabuti em uma planta que ajudaria na caça de jabutis, o que poderia ser interpretado como a explicação da origem da magia atribuída à planta. De fato, o traço etiológico existe, mas é resquicial a ponto de não aparecer em outras versões do ciclo do Jabuti. 
muitas metamorfoses de Makunaima; essa limitação mais acentuada do Jabuti combinada à astúcia que lhe é peculiar nos levam a considera-lo como uma versão desmitologizada do trickster ${ }^{3}$.

Por estar centrado nessa figura, o ciclo do Jabuti também se assemelha às histórias de tricksters, baseando-se na “oposição inteligência (astúcia) x parvoíce (simploriedade ingênua)" (MELETÍNSKI, 2015, p. 99) e, por isso, essas narrativas tendem a ser permeadas pela comicidade. É preciso, no entanto, levar em consideração o tipo de riso de que estamos falando.

Para isso, talvez, o melhor exemplo para a discussão seja “O Jabuti, a Anta e a Onça" (KOCH-GRÜNBERG, 1953, p. 138-141). Começaremos resumindo a primeira parte da narrativa, porque esta é mais interessante para a discussão. $\mathrm{O}$ Jabuti é obrigado a caçar uma anta para que a onça não lhe mate. Para isso, ele pede que a anta coloque seu pênis fundo em sua boca e urine, pois ele estaria com sede. A Anta o faz, e o Jabuti lhe morde. "A anta correu para lá e para cá, batendo a tartaruga [sic] contra as árvores. Mas o jabuti não largou; mordeu cada vez mais e matou a anta" (KOCH-GRÜNBERG, 1953, p. 139).

Nota-se que o motor da narrativa realmente é a oposição da astúcia do Jabuti x a tolice da Anta, então o riso de fato surge por se "fazer alguém de bobo" (PROPP, 1992). No entanto, nota-se a presença de elementos, como a urina e o pênis, o que indica uma comicidade popularesca, baixa, livre da solenidade das narrativas cosmogônicas e dos mitos antigos. Mediante a oposição do ciclo de

\footnotetext{
3 Por desmitologização compreendemos o processo de perda gradual das características míticas que compõe as narrativas mais antigas em versões cada vez menos concentradas, saindo de um deus com poderes cósmicos e chegando aos protagonistas modernos.
} 
Konewó ${ }^{4}$ ao de Makunaima5, nota-se que o ciclo do Jabuti está em algum ponto entre os dois, embora mais próximo das anedotas mitológicas de Konewó.

Feitas essas considerações a respeito do seu gênero, ficam mais claras algumas características do ciclo do Jabuti, mas ainda é preciso levantar algumas considerações a respeito do protagonista antes de começarmos a discussão do nosso tópico.

\section{O ETHOS DO JABUTI}

Em suma, as narrativas do ciclo do Jabuti podem ser consideradas como anedotas mitológicas por três razões principais: elas não apresentarem o traço etiológico, considerado um dos principais traços dos mitos antigos (MELETÍNSKI, 2019b); essa ausência nos permite depreender que sua principal função era o entretenimento; e o tipo de comicidade mais presente nas narrativas está ligado ao logro do outro e ao escatológico.

Embora tenhamos abordado algumas características sobre o protagonista em si mesmo, não nos detivemos em sua análise. Por isso, passaremos agora à discussão mais detalhada da composição do Jabuti.

Como dissemos, o ciclo é marcado pelo embate entre um protagonista astuto e seu antagonista tolo, mas isso não implica necessariamente na vitória do protagonista. Ao competir com outros animais, o Jabuti geralmente perde se não recorre à astúcia. É o caso, por exemplo, da história narrada por Dikboba Suruí (MINDLIN, 2007, p. 121) a respeito de uma competição entre o Jabuti (chamado

\footnotetext{
4 As narrativas desse personagem são típicas anedotas mitológicas, cuja função principal era o entretenimento dos ouvintes. Os antagonistas mais frequentes são as Onças, clara expressão do binômio força bruta da natureza $x$ astúcia humana. Por serem destinadas à diversão, o ciclo de Konewó não apresenta o traço etiológico.

5 Apesar de muita controvérsia a respeito dessa figura, o ciclo de Makunaima está muito próximo das narrativas de trickster mitológicos, tendo uma forte presença da etiologia típica dos mitos antigos, explica-se, por exemplo, a razão das peculiares formações rochosas do monte Roraima ou a distribuição das frutas.
} 
Amoa nas narrativas dessa etnia) e a Arara (Kahar). Algumas mulheres encontram Amoa perto de uma árvore frutífera e pedem que ele pegue algumas frutas para elas, mas Amoa não consegue por ser desajeitado. Em seguida pedem a Kahar, que traz frutas em abundância. Esse primeiro movimento da história, baseado unicamente na capacidade física, se encerra com a derrota do Jabuti. Em seguida começa o segundo arco da trama, pois, irritado com a Arara, o Jabuti resolve se vingar: ele embriaga a Cobra (Hobô) e a convence a matar Kahar. Notase que o Jabuti não foi capaz de realizar a tarefa que lhe foi imposta, porque ela depende da capacidade física, mas ao final triunfa por utilizar-se de artimanha para vencer seu rival.

De modo geral, o Jabuti consegue rivalizar com os principais atributos de outros animais ao utilizar a sua particular astúcia. É o caso de “O Jabuti e o Veado" (COUTO DE MAGALHÃES, 1876, p. 185-191), em que os personagens resolvem disputar em uma competição de velocidade ${ }^{6}$. Na história indígena, os dois animais apostam uma corrida, cada um em uma margem de um rio. Para medir a distância, o Veado chamaria o Jabuti e esse responderia para que pudessem saber quem estava na frente. Depois de combinarem os termos da corrida, o Veado permite que o Jabuti comece a corrida na frente, convencido que sua velocidade era muito superior. O Jabuti, então, chama todos os seus parentes, outros jabutis, e os esconde ao longo da sua margem do rio. Sempre que o Veado chamava o Jabuti, um de seus parentes respondia, dando a impressão de ele sempre estar à frente. De tanto correr, o Veado acaba morrendo de cansaço, e, assim, o Jabuti vence a competição.

Como se pode notar, ao contrário do que ocorre na famosa história da Tartaruga e a Lebre, não é o consistente esforço do Jabuti que vence a disputa, mas sua artimanha. Nesse sentido a clara oposição entre o ethos da Tartaruga da fábula, marcada pela persistência, e o Jabuti, cuja sagacidade é o traço principal,

6 Não confundir com a “Tartaruga e a Lebre” (DEZOTTI, 2018, p. 77). 
afeta a própria composição da narrativa, muito menos desenvolvida em sua forma grega. É importante ressaltar que há certa crueldade no Jabuti, que não é afetado pela morte do Veado.

Outra razão para a necessidade da astúcia, que decorre da primeira, é a falta de mecanismos de defesa mais evidentes, como dentes e garras. Essa ausência serviu de motivo para uma história contada por Ipokarã, membro da tribo Paiter-Suruí, registrada por Mindlin em sua antologia (MINDLIN, 2007, p. 83). Em suma, Pamoiei zomba de Amoa por sua boca não ter dentes, por isso se parece com uma vagina. Ofendido, Amoa convence Pamoiei e seus dois irmãos a colocarem o pênis na boca dele, pois lhes seria muito bom. Feito isso, Amoa morde e arranca os membros dos três irmãos, que morreram em seguida. Como vimos, esse motivo se repete também na cultura taurepangue, em que o pênis cortado é o da Anta.

Embora ele nem sempre seja vitorioso nas disputas contra outros personagens astutos 7 , basta-nos o esclarecimento a respeito da capacidade do Jabuti de recorrer a táticas pouco nobres, como a usada para castração dos seus rivais.

\section{O SELVAGEM, DE COUTO MAGALHÃES}

Feitas essas considerações iniciais a respeito do ciclo do Jabuti como um todo, passaremos à discussão da versão encontrada em O Selvagem, de José Vieira Couto de Magalhães, um curso rápido de tupi publicado em 1876, que traz um corpus de histórias no idioma original e suas narrativas interlineares.

Como se nota já pelo título, o livro apresenta certa datação histórica que deve ser levada em consideração ao trata-lo como documento, principalmente

\footnotetext{
7 A história "Iauti Oiuiuanti Macacaitá Irumo" (MAGALHÃES, 1876, p. 191-192) é um exemplo claro de como a astúcia do Macaco vence a esperteza do Jabuti.
} 
em relação ao tema da superioridade da "raça branca". À página 89, por exemplo, o estudante estaria aprendendo os comparativos e em seus exercícios de fixação lê-se: “Quem é melhor: o homem branco ou o homem negro?" a que se responderia o interlocutor "O branco é melhor que o preto", e o caso se repete em relação à beleza superior do homem branco em relação ao vermelho. $\mathrm{O}$ autor também se refere aos povos indígenas como "bárbaros", "selvagens" e defende que se "domestique os selvagens". Hoje em dia as posições do autor seriam consideradas crime inafiançável, mas trata-se, vale a pena repetir, de um texto de 1876. É preciso levar em consideração a inserção histórica do documento para não incorrer em uma leitura anacrônica; isso não significa, no entanto, que esse dado não seja significativo e tenha muito a dizer sobre nossa cultura. Infelizmente não teremos espaço suficiente para uma análise detida das ocorrências desse tipo no documento.

Isso posto, voltaremos nossa atenção especificamente para a história VIII, "Iauti Micura", traduzida por Magalhães como "O Jabuti e a Raposa" (COUTO DE MAGALHÃES, 1876, p. 199-203). A trama não chama a atenção, pois é um exemplo típico das narrativas do ciclo do Jabuti: o Jabuti estava tocando sua flauta, cujo som agrada à Raposa. Ela pede para tocar a flauta, e o Jabuti a princípio não permite; a Raposa o engana e foge com o instrumento musical. Para se vingar, o Jabuti faz uma armadilha, engana e prende a Raposa, obrigando-a a devolver sua flauta. Trata-se de um embate de astúcias em dois movimentos. No primeiro, a Raposa vence, mas depois é vencida no segundo.

A questão de nosso principal interesse surge na descrição da armadilha feita pelo Jabuti, pois sua construção é explicada de maneira detalhada pelo narrador indígena, mas a versão de Couto de Magalhães tem uma lacuna. $\mathrm{O}$ trecho em questão é o seguintes:

\footnotetext{
8 Para preservar a estrutura textual apresentada ao leitor, que deixará clara a lacuna, citaremos o texto como em versão fac-símile, mas atualizaremos a grafia de algumas palavras como "pao" por "pau" a fim de facilitar a leitura do texto, já difícil o bastante. Vale ressaltar que a tradução
} 
Iáutí oçóãna cahá rupí ocika paraná

O jabuti foi bosque pelo, chegou do rio

remehipe, omunúca mirá omunhã arãma mitá, margem a, cortou madeira fazer para ponte

oiaçáu arãma i ári rupi; ocika çuaindá-

atravessar para cima por, chegou outra margem

pe, oiúpiri, omunúca íra mira, oiuúca mirá

na, trepou, cortou de mel arvore, tirou de pau

ira, oiuiri ãna çakaquera kete, ocika micúra

mel, voltou atrás para, chegou da Raposa

rapé pé, oiatica i akãin (akanga) iui pe,

caminho no, fincou sua cabeça chão no,

opicika mira íra, omumúri xiquára pé.

pegou de pau o mel, ungiu [....].

(COUTO DE MAGALHÃES, 1876, p. 201-202)

O ruído que nos interessa na comunicação é justamente a supressão das duas últimas palavras da citação. Por algum motivo a expressão "xiquára pé" não foi traduzida. A última palavra, "pé" equivale, de acordo com a tradução de Couto de Magalhães, à preposição “em”, então o Jabuti passou o mel em algum lugar usando um galho, o que nos parece absolutamente anódino. Resta-nos dúvida apenas quanto ao lugar em que se passou o mel, "quára". Deixemos isso assim por enquanto.

Depois de preparada a armadilha, a descrição de como a Raposa cai na armadilha também é significativa. A Raposa e sua amiga se aproximam da armadilha, então a Raposa "enfia o dedo" ali e lambe o mel, o que a deixa muito satisfeita, mas sua amiga a adverte:

do texto se dá palavra por palavra, inserindo-a imediatamente abaixo do seu original, por isso a sintaxe em português parece tão estranha. 
- Mãhân! Íra

- Que! Mel

Nhahã? Anhen! Iautí riquára nhahã, maí

Aquilo? Qual! Do jabuti é .... aquillo, como

Tahá?" Amù oçuaxára: - Mahã iáutí riquára

Então? A outra respondeu: - Que de jabuti ....

Quahá! Ira quahá, mai tahá?

Isso! Mel é isso, como então?

(COUTO DE MAGALHÃES, 1876, p. 202)

Como se pode notar, a ausência da tradução de "quara" não pode ser gratuita, pois é recorrente. A partir dessa constatação, surge nossa primeira hipótese para essa supressão: desconhecimento da palavra. Considerando que o livro é um manual do idioma, certamente essa opção seria pouquíssimo provável. A fim de colocarmos essa hipótese à prova, fizemos uma varredura por outras ocorrências do vocábulo ao longo do livro. Surpreendentemente a raiz "quara" nem sempre tem sua tradução omitida, e o cotejo das variações nos mostra que não se trata do prefixo "ri-“ que causa sua supressão. Por exemplo, na história do ciclo do Jabuti aqui analisada, nos deparamos com a seguinte passagem:

Iáutí oikí iui quára úpe Jabuti entrou do chão buraco em. (COUTO DE MAGALHÃES, 1876, p. 204)

Claramente "quára" é traduzido por "buraco", opção reiterada duas vezes à página 75 , mais duas à página 197 , outra à 206 . Uma tradução alternativa é encontrada às páginas 247 e 260, "cova”. Há uma exceção à página 211, que apresenta a variante "caixa". Se antes a dúvida surgia por causa da ausência de tradução, diante desses novos dados, ela precisa ser reescrita da seguinte forma: se há tantas ocorrências traduzidas da palavra, por que as ocorrências dessa narrativa em específico são suprimidas? 
Como deve ter ficado claro até aqui, o campo semântico de "quára" parece estar ligado principalmente a buraco, toca ou cova. Repetiremos, então um trecho já citado da história do "Jabuti e a Raposa".

rapé pé, oiatica i akãin (akanga) iui pe,

caminho no, fincou sua cabeça chão no,

opicika mira íra, omumúri xiquára pé.

pegou de pau o mel, ungiu [....].

(COUTO DE MAGALHÃES, 1876, p. 201-202)

O Jabuti enfia a cabeça no chão e "unge" a "quára" com o mel. Em seguida, a Raposa é atraída pelo chamariz, passa o dedo, experimenta o mel e é advertida pela companheira que aquilo era um "quára" de jabuti. Ela não acredita e introduz a língua, então o Jabuti

Oiuica xi quára

Apertou seu ....

(COUTO DE MAGALHÃES, 1876, p. 203)

Em primeiro momento, se poderia supor que a "quara" apertada seria a boca, uma possível variação do motivo da castração, bastante recorrente no ciclo do Jabuti. Nessa trama, o Jabuti engana a Anta e a faz colocar o pênis em sua boca, em seguida castrando o pobre animal, que acaba por morrer. No entanto, não haveria razão para supressão dessa palavra que em nada ofenderia o leitor, sendo, no máximo, a menção a um beijo, evento recorrente na literatura romântica, por exemplo. O papel principal para se descartar essa interpretação é desempenhado pelo pronome possessivo: apesar de suprimir o substantivo, Magalhães opta por concordar o pronome possessivo com um substantivo masculino, não feminino, como "boca". Ainda que se ignorasse essa particularidade, vale relembrar que o Jabuti tinha enfiado a cabeça no chão para preparar a armadilha. 
Descartada, então, a opção da boca, resta-nos que o orifício corporal passível de ser apertado conforme a vontade de seu detentor seria o ânus. Aceitando essa interpretação, teríamos que o Jabuti se esconde no chão (enfiando a cabeça na terra) e lambuza o próprio ânus com mel para atrair a Raposa utilizando um galho. Apesar dos avisos de sua parceira, ela enfia a língua, talvez pensando ser uma colmeia de abelhas jataí, e é pega na armadilha do Jabuti. Sob ameaças de apertar com ainda mais força, a Raposa cede e devolve a flauta.

Considerando o tipo de humor praticado nas versões do ciclo do Jabuti discutidas anteriormente, o tom que essa interpretação dá à narrativa não está fora do encontrado em outras anedotas mitológicas, tampouco distorce a caracterização do Jabuti. Bastaria que o leitor se remetesse à narrativa completa da castração da Anta (KOCH-GRÜNBERG, 1953, p. 138-141), discutida anteriormente, para se certificar da nossa afirmação.

Para concluir, retomamos a questão do gênero literário a que atribuímos as narrativas do ciclo do Jabuti, isto é, as anedotas mitológicas, cujo objetivo principal é o riso. No caso da história VIII registrada por Couto de Magalhães e analisada aqui, o clímax cômico da história é a captura da Raposa. Dessa forma, ao suprimir essa passagem, o tradutor anula toda a potência da narrativa e, portanto, só poderia tê-lo feito de maneira consciente.

Em nossa opinião, a ausência de tradução para a palavra "quara" especificamente nesse contexto pode ter sido uma exigência do mercado editorial brasileiro da época, pois a cena seria considerada indecorosa para o público leitor, embora as anedotas populares sempre tenham sido vulgares. Lamentavelmente as comparações racistas apontadas anteriormente não tiveram o mesmo impacto, o que certamente não é fato a se ignorar da nossa cultura.

Para embasar nossa hipótese, apontaremos uma evidência que a confirma. No conto XXI, intitulado "Micura iauaraté" ("A Raposa e a Onça"). A Onça resolve se fingir de morta para enganar os demais animais, mas a Raposa não se 
dá por convencida e pergunta se a Onça já teria arrotado. Ao perceber o crescente ceticismo dos animais convencidos pela Raposa, a Onça resolve arrotar, revelando, assim, que não estava morta.

O autor comenta o verbo "arrotar" em nota de rodapé da seguinte forma: "Vera significatio hujus verbi - pinõ - est flatus ventris" (COUTO DE MAGALHÃES, 1876, p. 261). Ao contrário do que acontece em todas as outras notas de fim de página ao longo do livro, essa é a única no idioma latino, o que reforça a hipótese de haver certo desconforto em lidar com temas escatológicos. A partir disso, podemos supor que o uso do latim causaria certo distanciamento entre o leitor e o enunciado, o que seria considerado menos agressivo para o leitor.

Outra possibilidade que explicaria a utilização do latim nessa nota de rodapé decorreria de o latim ser uma língua de pouca acessibilidade, não permitindo que certos grupos, como as crianças, tivessem acesso a essa leitura.

A julgar, portanto, pela cena descrita pelo narrador, seria muito difícil encontrar uma forma amena de se descrever a artimanha usada pelo Jabuti para enganar a Raposa. Dessa forma, Couto de Magalhães preferiu simplesmente omitir a tradução, deixando a cargo do leitor a interpretação dessa palavra.

\section{REFERÊNCIAS}

COUTO DE MAGALHÃES, José Vieira. O Selvagem. Rio de Janeiro: Typografia da Reforma, 1876. Disponível em: http://www.etnolinguistica.org/biblio:magalhaes-1876selvagem. Acesso em: 20 mar. 2021.

DEZOTTI, Maria Celeste Consolin (org). A Tradição da Fábula: de Esopo a La Fontaine. São Paulo: Editora Unesp, 2018.

KOCH-GRUNBERG, Theodor. Mitos e Lendas dos índios Taulipang e Arekuná. In: Revista do Museu Paulista, Nova Série v. VII, pp. 9-202. São Paulo: Museu Paulista, 1953. Disponível em: http://www.etnolinguistica.org/biblio:koch-grunberg-1953-mitos, Acesso em: 20 mar. 2021. 
MELETÍNSKI, E. M. Os Arquétipos Literários; tradução Aurora Fornoni Bernardini, Homero Freitas de Andrade, Arlete Cavaliere. Cotia: Ateliê Editorial, 2015.

MELETÍNSKI, E. M. Ot Mifa k Literature. Moscou: RGGU, 2019a.

MELETÍNSKI, E. M. Mito e Conto Maravilhoso: Tradução de Rafael Bonavina e Ekaterina Vólkova Américo. RUS (São Paulo), São Paulo, v. 10, n. 13, p. 149-164, 2019b. Disponível em: https://www.revistas.usp.br/rus/article/view/155845. Acesso em: 16 jan. 2021.

MINDLIN, Betty. Vozes da Origem. Rio de Janeiro: Record, 2007.

PROPP, Vladimir. Comicidade e Riso. São Paulo: Ática, 1992.

Nota do editor:

Artigo submetido para avaliação em: 27 de março de 2021.

Aprovado em sistema duplo cego em: 02 de setembro de 2021. 